2009

\title{
Student Perceptions of Learning Disability Labels at the Junior High and High School Level
}

Ashley L. Matheson

Cedarville University

Follow this and additional works at: http://digitalcommons.cedarville.edu/education theses

Part of the Special Education and Teaching Commons

\section{Recommended Citation}

Matheson, Ashley L., "Student Perceptions of Learning Disability Labels at the Junior High and High School Level" (2009). Master of Education Research Theses. 23.

http://digitalcommons.cedarville.edu/education_theses/23 


\title{
STUDENT PERCEPTIONS OF LEARNING DISABILITY
}

\section{LABELS AT THE JUNIOR HIGH AND HIGH SCHOOL LEVEL}

\author{
A thesis submitted in partial fulfillment \\ of the requirements for the degree of \\ Masters of Education
}

By

ASHLEY L. MATHESON

2009

Cedarville University 
CEDARVILLE UNIVERSITY

SCHOOL OF GRADUATE STUDIES

January 31, 2009

I HEREBY RECOMMEND THAT THE THESIS PREPARED UNDER MY SUPERVISION BY Ashley L. Matheson ENTITLED Student Perceptions of Learning Disability Labels at the Junior High and High School Level BE ACCEPTED IN PARTIAL FULFILLMENT OF THE REQUIREMENTS FOR THE DEGREE OF Master of Education.

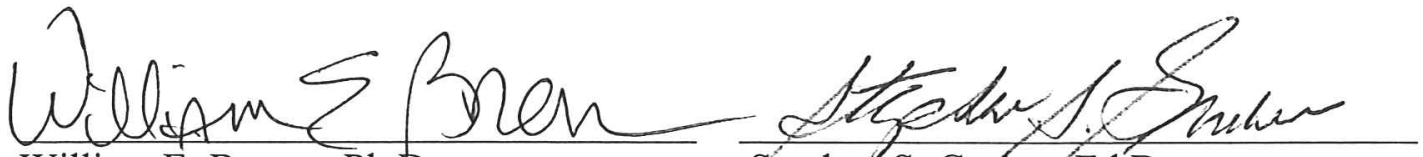

William E. Brown, Ph.D.

President

Stephen S. Gruber, Ed.D.

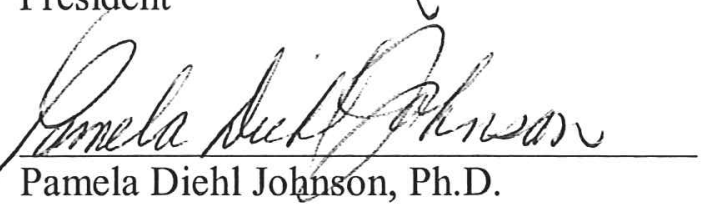

Education Department Chair

Thesis Advisor

Dean, School of Social Sciences

and Human Performance 


\begin{abstract}
Matheson, Ashley L. M.Ed., Education Department, Cedarville University, 2009. Student Perceptions of Learning Disability Labels at the Junior High and High School Level.

This qualitative research study provides student perceptions of their own Learning Disability labels at the Junior High and High School level. All thirty-five students who were involved answered questions during in-depth interviews. The students represented a sample population of small, rural, and public junior high and high school students. Interview questions focused on the benefits and limitations of being labeled with a learning disability. Data analysis results showed that students preferred being in special education or being labeled as learning disabled because they are able to gain help in order to be successful in school. Limitations and negative aspects were also noted and taken into account in this study. This information within this study can be used for educators to gain more insight into the personal opinions and perceptions of his or her LD students.
\end{abstract}




\section{TABLE OF CONTENTS}

CHAPTER I: Introduction...................................6

Definition of Terms..................................9

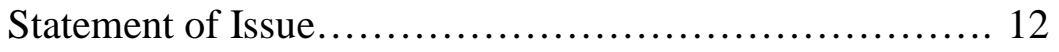

Scope of the Study and Delimitations.................. 13

Significance of the Study........................... 14

Methods of Procedure ................................ 15

CHAPTER II: Plenary Literature Review ......................17

History of Special Education........................... 17

Relevant Theories in LD Students Academically............ 18

Relevant Theories in LD Students Socially................19

Perceptions of LD labels..............................21

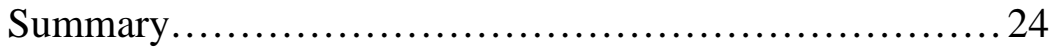

CHAPTER III: Methodology................................26

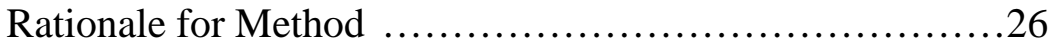

Population of the Study................................27

Sample.............................................27 
Procedure.

CHAPTER IV: Qualitative Findings ..........................31

Description of Data...................................32

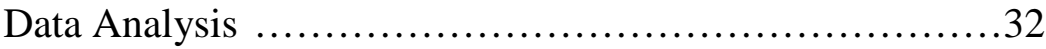

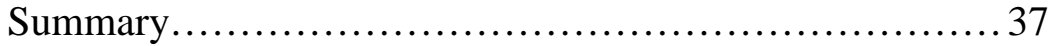

CHAPTER V: Discussion and Implications .....................39

Interpretation of the Results ............................39

Potential Applications of the Findings....................42

Biblical Integration......................................44

Relation of the Results to Literature.......................45

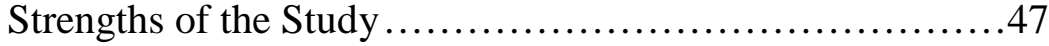

Limitations of the Study.............................. 48

Suggestions for Future Reference........................49

\section{APPENDICES}

APPENDIX A: Interview Questions .....................51

APPENDIX B: Parental Consent Form ...................53

REFERENCES..........................................54 


\section{Chapter 1}

Introduction

Prior to WWI, most students labeled mentally retarded were served educationally in institutions. The number and types of students who received special education services expanded post-WWI. Schools implemented special education classes, and special education schools were formed during the 1960s (Irvine, Wright, \& Applequist, 2007). The U.S. public school system was clearly moving toward a Least Restrictive Environment.

Least Restrictive Environments (LRE), also known as inclusion, surfaced during the 1970s when students were mainstreamed more frequently into the regular classroom (Irvine et al., 2007). The law that mandated this was found in Public Law 94-142. One of the major components of PL 94-142 was a free and appropriate public education for all children. Later Public Law 101-476 or IDEA was passed with additional elements. The shift in LRE was greatly questioned and continues to be an issue in today's educational systems (Irvine et al., 2007).

Present day legislation includes the passage of No Child Left Behind (NCLB) in 2001. The goal of this law is to examine students on Individualized Education Plans (IEP) by setting goals and measuring their success or failure according to the goals established by a team of educators, parents, and the student (Irvine et al., 2007). 
Children who experience Learning Disabilities (LD) in today’s U.S. public schools are an estimated 2\% of the total population. Under the umbrella of special education, LD students are the single largest group served. The first mention of the term Learning Disability was used at the Chicago Conference on Children with Perceptual Handicaps in 1963 (Swanson \& Edelston, 2007).

Conley (2007) states in his findings that students labeled as Learning Disabled have problems with academic growth and achievement. Therefore, labels are many times condemned because they limit one's self-perception. Others including peers, teachers, and parents may also perceive the student in a negative light. The child that is labeled LD will at times attribute their triumphs or failures in school dependent upon the label. Individuals labeled LD in this study found themselves less inclined academically to those who were not labeled. These individuals attributed their successes or failures in school to their disability (Banks, 2008). Schmidt \& Cagran (2008) report through their findings that students in the regular classroom setting who are labeled LD have lowered academic self-concept than their peers who do not have learning disabilities.

Lauchlan \& Boyle (2007) found that labeling can have positive and negative outcomes. Labels tend to lead to intervention for a student, which in turn fabricates gains in learning. Many labels are deemed indispensable in order to plan for the curricular and social need of the labeled children. On the other hand, others argue that labels don't necessarily provide solutions.

Students often feel rejected by their peers when labeled with a learning disability. Students labeled as LD often experience rejection from their peers as they interact at lunch, in the classroom, and after school activities. These students are less likely to be 
picked for teams, and are often times disregarded and/or rejected by their peers. These students feel less proficient in academics and social skills than the regular education students (Zic \& Igric, 2001). These students who feel rejected by others tend to be more hostile, have lowered self-esteem, emotional instability, and a negative view of the world (Mrug \& Wallander, 2002).

In one case study on an individual with Asperger's disorder, the student felt accepted by her teacher, but not by her peers. She shared an account when two male students teased and picked on her by blowing paper wads through a straw. She shared that these students mostly teased just her, but she explained how she was used to it because they did it all the time (Mayton, 2005).

Another study found that students labeled with High Functioning Autism, experienced fewer social interactions during the school, had fewer friends, and were more likely to be bullied by other students (Wainscot, Naylor, Sutcliffe, Tantam, \&Williams, 2008). All participants in this study communicated various levels of verbal abuse and social exclusion from their peers. In order to avoid such situations, the students with High Functioning Autism avoided other students during free times at school (Wainscot et al., 2008).

On the other hand, according to Lauchlan \& Boyle (2007), students can experience academic benefits from being labeled as LD. Some will seek the attention that is needed to derive a diagnosis in order to explain his or her problems. A fifteenyear-old girl states that the diagnosis of her LD was "like the sun coming out after a cold day of rain” (Lauchlan \& Boyle, 2008). Her encouragement was for students to use labels, but not to allow themselves or others to identify them by it. Yet another student 
within this study expressed that he was no longer under the impression that he was unintelligent, since he was diagnosed with a LD. The weight had been lifted off of his chest and therefore he could move on with his life.

Over the past 40 years, many laws have been implemented concerning special education and students who are labeled as LD. It is no wonder that research continues to discover mixed findings on the topic of LD students. This paper will consist of the study results that have been discovered concerning special education students. More specifically I hope to uncover what it is like to be labeled and how such a label affects students socially and academically.

\section{Definition of Terms}

Bullying- The systematic (repeated) abuse of power (Wainscot, et al., 2008). Disability- A physical, psychological, or neurological deviation in an individual's makeup. A disability may or may not be a handicap to an individual, depending on one's adjustment to it. The terms disability and handicap often have been considered and used synonymously, but this is not accurate, as a handicap actually refers to the effect produced by a disability. With the passage of IDEA, the field has shifted to the use of disability and has usually abandoned the use of handicap (Vergason, 1997).

\section{Education for All Handicapped Children Act of 1975 (Public Law 94-142)- A}

federal law, described as a "Bill of Rights for the Handicapped," that includes many provisions and special features designed to protect the rights of children with disabilities. It includes provisions for free appropriate public education, definitions of the various handicaps, priorities for special education services, protective safeguards, and 
procedures for developing mandatory Individualized Education Programs (Vergason, 1997).

Free and Appropriate Public Education (FAPE)- One of the key stipulations of PL 94-142 and IDEA requires an educational program for all children without cost to parents. This stipulation does not require the best possible education, but when combined with the LRE, it implies that the individual is to receive the education and related services that will bring about an adequate program (Vergason, 1997).

Global Self-Worth-The overall evaluation of one's worth or value as a person (Bear, Minke \& Manning, 2002).

Least Restricted Environment (LRE)/Inclusion- A term connoting the expectation that for the majority of students with disabilities the least restrictive environment is general education with support. Inclusion does not mean full-time enrollment in general education, but connotes that it is the preferred placement for all students and that the majority of all services will be delivered there (Vergason, 1997).

Individualized Education Plans (IEP)- A component of the Education for All Handicapped Children Act, which requires a written plan of instruction for each child receiving special services; gives a statement of the child's present levels of educational performance, annual goals, short-term objectives, specific services needed by the child, dates when these services will begin and be in effect, and related information. The program is undertaken by a team that includes the parents (Vergason, 1997).

Individuals with Disabilities Education Act IDEA (Public Law 101-476)- When PL 94-142, the Education for all Handicapped Children Act, was first updated during the one hundred and first congress (PL 101-476), it was renamed the Individuals with Disabilities 
Education Act. The new act carried forth all the provision of the PL 94-142, but also included additional elements (Vergason, 1997).

Institutions- A public or private facility or building providing specified services to persons on a 24 hour residential basis (Vergason, 1997).

Learning Disability/Learning Disabled- Those individuals who are of normal intelligence but suffer mental information processing difficulties (Swanson \& Edelston, 2007).

No Child Left Behind (NCLB)-The No Child Left Behind Act of 2001 substantially increases the testing requirements for states and sets demanding accountability standards for schools, districts, and states with measurable adequate yearly progress (AYP) objectives for all students and subgroups of students defined by socioeconomic background, race-ethnicity, English language proficiency, and disability (Linn, 2002). Self-concept/Self-perception- An individual's awareness of his/her own identity (Schmidt \& Cagran, 2008).

Self-esteem- How participants feel about themselves generally in an overall sense (Conley, 2007).

Special Education: A broad term covering programs and services for students who deviate physically, mentally, or emotionally from the norm to an extent that they require unique learning experiences, techniques, or materials in order to be maintained in the general education classroom, or in specialized classes and programs if their problems are more severe. As defined by Public Law 101-476, special education is specifically designed instruction, at no cost to the parent, to meet the unique needs of a student with a 
disability, including classroom instruction, physical education, home instruction, and instruction in hospitals and institutions (Vergason, 1997).

Visual Impairment- In education, defined as a deficiency in eyesight that is great enough that the student requires special provisions. The student may be blind or partially sighted (Vergason, 1997).

\section{Statement of Issue}

With the influx of student labels in the realm of special education, there are many questions and concerns that arise. A substantial amount of time, money, and research has been poured into making special education the most effective and efficient it can possibly be. LD and special education have been thoroughly studied, although, the effects of those labels on students have not been. Since teachers and regular education peers come into contact with students labeled as LD everyday, it is necessary to press on and study the effects that labels have on special education students socially and academically. Assessing a specific age level is needed since experiences across multiple age levels have provided us with mixed results. Students’ responses may differ greatly among elementary, junior high, and high school. The particular age groups I will focus on will be the junior high and high school level. The junior high and high school level will consist of seventh through 12th-grade students.

Researchers, parents, and school psychologists continue to be concerned with the negative effects that labels can have on students. Self perception is a recurring issue that researchers continue to bring to the forefront. Participants in one study felt they lacked academically compared to other students, solely because they were unable to control the 
outcomes of their performances. This suggests that student perception is often times more important than teachers' perceptions. This brings a great issue to the forefront of special education and may explain why students labeled LD may experience failure academically (Banks \& Woolfson, 2008).

Since junior high and high school can be a difficult time for many students, being labeled LD also can pose a threat to relationships in the social realm of schooling. One study shows these labels create feelings of loneliness and segregation in special education students from the normal population of students (Ho, 2004 ). Feelings of loneliness and rejection by others can lead to negative self images and sometimes even depression. Enhancing the self-concept of students with special needs can result in positive effects on his or her social connections and academic life (Schmidt \& Cagran, 2008). In order to see if these findings are consistent, I will be addressing the benefits and disadvantages in seventh through 12th-grade students at the junior high and high school level.

\section{Scope of the Study and Delimitations}

In this study I will collect data from students labeled LD, and reflect on their perspectives. I will also assess issues where students communicate concern for improvements from educators and peers on being labeled. This study will be performed at a rural, public high school with an enrollment of approximately 400 students. This project will focus on junior high and high school students who are labeled LD in the seventh through 12th-grade levels. With regards to the scope of this study, the results made will be generalized to other local public schools of the same approximate size as Franklin-Monroe. 
This project will focus only on students who are labeled as LD and their views of the attached labels. Teacher perceptions will not be considered as a part of this study. Also, regular education students' perceptions will not be considered as a part of this research study.

Significance of the Study

Although Special Education has come a long way from the institutions that existed prior to WWI, parents and children still raise the question as to whether or not labels are beneficial or harmful to the individual (Ho, 2004). It is no wonder that some individuals tend to shy away from labels. Between 1900 and 1970, children who were labeled as visually impaired or as learning disabled were often institutionalized and were not provided quality educations, if any education at all. Many times those in charge were oppressive and abusive to the children. The LD children were also bullied by other children in the institutions. The bullies were many times reinforced by the staff for their behavior (French, 2007).

Other studies that have been done demonstrate that labeling a child can affect other people's perceptions as well. Special Education children studied in the UK revealed that discrimination still exists amongst educational settings. Placing labels on students with LD may indeed help them better cope with the disability, but often the threat of being inferior to the normal population lies within. Although many developed countries, including the U.S. have passed laws to prevent discrimination and placed students in the LRE, there are still many schools and teachers who perceive learning disabled students as inferior to the general population (Ho, 2004). Consequently, educators need to know what it is like for an individual to be labeled LD and whether it is 
valid to do so. It is crucial to research feelings and emotions attached to a label so educators can better understand the positive and negative aspects that are attached to these labels.

The perceived benefits/limitations of being labeled LD must be investigated. If students, teachers, and parents do not recognize value in the use of labels, then we must question their validity. On the other hand, if students, teachers, and parents do view LD labels as a valuable mean to a student's life socially and academically, then it should be further encouraged. Research has been done on labeling special education students in the school systems, but researchers have found mixed results (Schmidt \& Cagran, 2008).

\section{Methods of Procedure}

Research questions:

1. How does it feel to be labeled as a special education/learning disabled student in the public school system?

2. How does this label affect a student who is labeled LD in his or her social relationships and academics?

This research will focus on my students' perceptions of being labeled as Special Education/LD. The research will be conducted in a qualitative manner with a phenomenological design. It will be an inductive approach in which I collect data, and then form a hypothesis from the information. The data will be collected in the form of peer-reviewed journals, books, encyclopedias, and interviews. In studying the data, I anticipate concluding several reoccurring themes in order to find the benefits and disadvantages of LD labels. 
In order to better understand the students' views, interviews will be conducted with 35 junior high and high school students who are labeled LD. This interview will consist of 15-20 questions that reflect the feelings and attitudes of the participants. The interviews will take approximately 20 minutes each and will be recorded by a Dictaphone. After recording the interviews, I will transcribe the information.

When I analyze the data, I will undertake the process of coding in which I will look for common themes among the three constructs. I will compare the recurring themes throughout the coding process and I will remove the codes that are not repeated. Throughout the coding process I will also add recurring themes that emerge from the data. 


\section{Chapter 2}

\section{Plenary Literature Review}

\section{History of Special Education}

The passing of PL-142 brought about much debate over the positive and negative consequences of different educational placements for students with disabilities. Students receiving special services can be educated anywhere from fully separated schools to fully integrated classrooms (Elbaum, 2002). Including students with disabilities in the regular classroom has greatly increased over the past fifteen plus years. These changes were brought about the mid 1980s due to low academic performance, and ongoing demands for social equality of LD students; not to mention, the cost of special education was soaring (Rea, McLaughlin, \& Walther-Thomas, 2002).

Subsequently, the number of students being served in resource rooms or separate classrooms has diminished (Fore, Hagan-Burke, Burke, Boon, \& Smith, 2008). Since the mid 1980s, education has seen a great shift by serving a large number of students with disabilities within the regular education setting (Rea et al., 2002). The only time a student with a disability can be taught in a separate environment is when adequate academic progress cannot be met in the regular classroom with special education services and supports (Elbaum, 2002).

Over a ten year span between 1986 and 1996, students with learning disabilities who were educated in regular classrooms increased by a dramatic 20\% (Holloway, 2001). Today, 99\% of children with LD in the United States are educated in regular classroom 
settings. Sixty percent of these students receive education in either a resource room or in a special education class (Bakker, Denessen, Bosman, Krijger, \& Bouts, 2007).

In a landmark case, Daniel, R.R. v. State Board of Education (1989), the court upheld that one of the fundamental benefits of LRE was "the non-academic benefits to the child of interaction with non-handicapped children.” Therefore to this day LRE cannot be rebutted simply by showing that a special education placement is academically superior to a regular education classroom. The benefit of positive peer behavior models is one of the non-academic advantages of educating a student in the regular classroom setting. This in turn has accounted for increased social acceptance, improved social skills, greater friendships, and higher self-esteem (Elbaum, 2002).

\section{Relevant Theories in LD Students Academically}

In hopes of combating the lack of social skills of children with disabilities, integrating them into the general classroom was the solution of LRE laws (Bryan, Burstein \& Eurgul, 2004). The success of the inclusive classroom setting has been questioned since its conception of LRE in the 1970s (Holloway, 2001). Some parents express concerns and oppose LRE and state that their students who are in inclusive settings have academic difficulties and need to be instructed apart from the regular classroom setting (Elbaum, 2002). Some research has found insignificant conclusions for students taught in a LRE as opposed to students placed in more traditional special education classes. The educational needs of these students in a LRE were not being completely met. Only some of the educational needs of these students were met (Holloway). 
Other researchers have found that the two separate programs (inclusive vs. pullout special education programs) differ greatly academically. The results of one test shows that students who were served in an inclusive classroom setting had earned significantly higher grades than those who were served in a pullout special education classroom. These students scored higher in all four subject areas, which included the following: language arts, mathematics, science, and social studies (Rea et al., 2002).

This research is limited especially at the secondary level. Other researchers found that students in elementary schools achieve more academically in inclusive settings rather than special education classes. Similarly in middle school settings researchers have also found that students are more academically successful in inclusive settings. These students had higher grades, fewer behavioral issues, and had higher school attendance than those in special education classroom settings (Fore et al., 2008).

On the contrary, students labeled LD also demonstrate lower levels of academic self-concept than students without labels. Because self-concept is multidimensional, it not only plays a huge part in a student's life socially, but also academically (Elbaum, 2002). Research is limited on the academic achievement and social outcomes of students with LD. The findings are not conclusive (Fore et al., 2008).

\section{Relevant Theories in LD students socially}

Close to 2,800,000 children in the United States have been identified as LD. Social problems also seem to infiltrate all ages including preschool, elementary, junior high, senior high, college, and adulthood (Bryan et al., 2004). One important aspect of social competence is a positive self-concept. Low self-concept in students with LD have been associated with various problems such as depression and learned helplessness 
(Elbaum, 2002). In terms of self-concept, students who are LD report mixed findings on their social status. Some researchers have found that LD students rate themselves more negatively on social skills. Other researchers have found just the opposite. Some LD students actually rate themselves high on their self-esteem on social factors (Bryan et al., 2004). Children with developmental disabilities express feelings of loneliness as high as $25 \%$ while non-LD students range only from $10 \%-18 \%$. It has also been found that students who are labeled LD were less popular than their peers (Bryan et al., 2004). In one study $75 \%$ of children with LD have problems with social skills deficits (Raskind, Margalit, \& Higgins, 2006). Because of these social skills deficits, studies have also found that 7-15 year olds who are labeled as LD are much more likely to experience loneliness than non-LD peers. Large numbers of these students have severe problems with self-control, aggression, and peer rejection. Yet others have been described by their teachers as withdrawn without problems of self-control (Wiener, 2004). Not only do these children have problems developing friendships, but they also have trouble maintaining friendships. Many students attribute these social issues to his or her LD (Raskind et al., 2006).

Other research has found that many students who experience academic problems also demonstrate behavior problems and social skill deficits. It is unclear though if children who are labeled as LD have lowered feelings of global self-worth (general happiness) or self-esteem. Many times a student's negative thoughts about himself or herself can be offset by other domains such as various skills and talents (Bear, Minke, \& Manning, 2002). 
Still other research shows that students with language impairments have poor social competence and are bullied by peers (Westby \& Blalock, 2005). Based on teacher ratings, social competence of LD students does not seem to be higher in inclusive settings than it does in non-inclusive settings (Bryan et al., 2004). Some internal difficulties associated with learning disabilities such as language impairment and ADHD can include anxiety/depression and becoming withdrawn from other students. External behaviors can include attention problems, aggressive behavior and rule-breaking actions. These external behaviors many times cause them to be rejected by their peers and then may lead to internal difficulties as mentioned above (Westby \& Blalock, 2005).

Some research shows that students who are labeled LD and placed in regular classrooms have higher self-concept levels than those who are educated in non-inclusive settings. Other studies have found no effect on LD students in either setting. Yet another study discovered that young children labeled as LD did not have lower self-concepts following being labeled.

\section{Perceptions of LD labels}

Many studies continue to find that children labeled as LD have low acceptance rates among peers and are less likely to be socially accepted by normal functioning peers (Wiener, 2004). In one study, teachers agreed that LD students are more disruptive, insensitive, less tactful, and act out in attention-seeking behavior more than their peers. Parents find that their student(s) with LD are less attentive, more active, and don’t follow directions or complete tasks well. Peers of LD students also rated them in a negative light saying they were more aggressive and disruptive (Bryan et al., 2004). 
One researcher concluded that peer acceptance of children with LD tends to drop during the school year. Students who have average social acceptance at the beginning of the year are neglected or rejected by students at the end of the year. Regular education students tend to perceive their LD peers more highly though, if they are in inclusive classroom settings. On the other hand, the perception of LD students in non-inclusive settings, such as students who go to a resource room is much more negative. There is high peer rejection and low peer acceptance of these students. One account shared by a student about an LD peer stated the following: "This girl right beside him moved her chair as far away from him as she could and she kept moving it over and trying to sit like this, so she was totally, with her body language and everything, removing herself away from him. I see the looks that they shoot him - like, you're weird...” (Wiener, 2004).

Some LD students expressed being treated differently from regular education students. They also expressed that teachers have lower expectations for them and that other students find them to be dumb. This all in turn can lead to low feelings of selfconcept which in turn affects them socially in a negative manner (Elbaum, 2002).

One young lady named Anna, a 13-year-old student, was studied and asked to give her story of living with a LD. Anna was diagnosed with a language LD at the age of 5. Through their study, the researchers found common themes of isolation, undervaluing, and oppression from other students. Anna demonstrated a low self-concept because of the frustration and anger she felt due to the label. She felt isolated because the only time she was educated with regular education students was during science and social studies. Other students in the sixth grade called her retarded. In the science class, the teacher had her sit at a separate table which caused negative feelings of sadness. When 
students were asked by the teacher to help her, she explained that they did help her, but that they did not want to (Reid \& Button, 1995).

LD students are also perceived as having fewer friends than students without LD. One regular education student reported that one student labeled as LD did not understand what a friend was. He described that the LD student thought that just because he knew twenty different people, that meant that they were all his friends. The student explained that just because you know someone doesn’t mean that they are your friend (Wiener, 2004).

Researchers in one study set up a website for LD children to write and voice themselves and ask questions to other children labeled with LD. Some children stated they felt stupid, and expressed that even their family perceived them as stupid. Others questioned if having a LD made them a nerd. Others disclosed loneliness by stating that they felt they were the only one with a LD. Others commented on having no friends as an example of their loneliness. The messages that were expressed by these students simply reinforced feelings of emotional distress, sadness, low self-worth, loneliness, and fear. All of these stemmed from the academic struggles they faced along with rejection from teachers, peers and even family (Raskind et al., 2006).

Students also feel victimized by their peers through bullying. Limited research has been conducted in this aspect of peer victimization on children with LD but the results conclude that children and adolescents with LD in elementary and middle school tend to be more likely to be bullied by their peers. The most common LD victims found were girls and children who were seen as shy by those who were bullies. Being bullied and having a LD tends to lend toward social and emotional problems (Wiener, 2004). 
One of the misconceived perceptions that teachers hold to is that it is not their responsibility to aide in peer relationships between LD children and regular education children. Teachers are bombarded with academic achievements such as standardized tests, that they are no longer able to create a healthy school environment for LD students. Their concerns many times are limed to on-task behaviors that affect the management of the classroom (Bryan et al., 2004).

\section{Summary}

With the number of different findings about inclusion in the classroom setting, it is crucial to assess its value. Inclusion surfaced decades ago when LRE was first introduced under PL 94-142 (Irvine et al., 2007). Since then, inconclusive research findings have led to mixed views on the effectiveness and usefulness of inclusion for LD students. Some researchers have concluded that inclusion is only capable of meeting the needs of some students. In order for inclusion to be a successful program for students labeled as LD, it is important that regular and special education teachers alike ensure that students receive the needed services in order to have a variety of learning opportunities (Holloway, 2001).

Others agree that inclusion creates an environment for students to be bullied and not socially excel (Westby \& Blalock, 2005). Inclusion students with LD experience difficulties academically, behaviorally, and socially. Students who are LD during childhood and adolescence are most likely to be socially neglected and rejected by their peers. This neglect occurs even more so with children who are labeled as LD in special education classrooms (Wiener, 2004). 
Many teachers, parents, students, and researchers have varying philosophical perspectives on the topic of LD students. Because of limited data, the debate continues on where to place these students, and which placement is most beneficial. Researchers agree that there has been limited research conducted on not only the academic achievements of LD students, but also their social outcomes (Rea et al., 2002).

In efforts to find student voices on their learning disabilities, limited information was available. Through one research-based paper, researchers gave LD students the opportunity to share their thoughts and feelings of their LD. In this study, researchers found reoccurring themes of sadness, low self-worth, loneliness, and fear. All of these feelings were derived from their academic struggles and social rejection. Because there is a limited amount of information on the opinions and voices of the actual students with LD, it is necessary to explore the voices of LD students and discover how labels affect them in not only their academic lives, but also their social lives.

The one and only certainty regarding class placement is that there is no conclusion. Researchers continually draw vastly different conclusions. These conclusions range anywhere from students with LD achieve more in special education classrooms, to inclusive versus non-inclusive have no difference in academic achievement, to the idea that students who are in inclusive classroom settings achieve more academically and socially (Fore et al., 2008). 


\section{Chapter 3}

\section{Methodology}

For this study, qualitative phenomenological research was performed by doing indepth interviews. The goal of this method of study was to analyze and assess students' perceptions of what it is like to be labeled as LD and how that affects them socially and academically. Students were asked a series of seventeen questions that allowed them to share his or her views of labels (See Appendix A).

Students were asked to participate in this study by spending approximately twenty minutes being interviewed. Students were pulled out of intervention time with teachers or during special education classes in order to participate in the interviews. Students were asked to share their own personal experiences, whether positive or negative, in light of their learning disabilities and special education classes.

\section{Rationale for the Method}

Phenomenological qualitative research is a common form of gathering information because it allows the researcher to understand a group of people from their own perspective. The researcher through interviews is painting a picture of what it is like to be this group of people. The issue I focused on throughout these interviews was the value of being labeled LD socially and academically for students who are in special education and/or on IEPs. With the questions that I focused on, I was able to discover the students’ perceived benefits and limitations of being labeled with a LD. 
As noted previously, a limited amount of research has been conducted on student's perceptions of being labeled LD, especially at the secondary level. Therefore, I proposed to ask a "how" question. My goal in this research was to know how students were affected socially and academically because of learning disabilities. In doing so, I sought out each student's personal experience in our school that are on IEPs from the junior high and high school level. By conducting in-depth interviews with these students, I was able to see firsthand their rich experiences in school. This goal was best met through phenomenological qualitative research in which in-depth interviews were conducted.

\section{Population of the study}

The population of the study consisted of seventh through twelfth grade students who were on IEPs at Franklin-Monroe High School. The results of this study have some degree of external validity of rural, secondary public junior high and high school students. The results of the study are most applicable to Caucasian students in the Midwest and of below average to average socioeconomic status.

Sample criteria. The students used in this research were the students at FranklinMonroe High School who are on IEPs. I interviewed all students who returned permission slips to participate in the study. A total of 35 students ranging from seventh grade to twelfth grade were interviewed.

Rationale for sample. I used junior high and high school students because all IEP students in those particular grade levels are intermingled in the high school setting. 
Those who are in special education classes may have classes with both high school-aged students and junior high-aged students.

Methods of sampling. Sampling consisted of all IEP students at the junior high and high school level who returned permission slips to participate. Only a few did not return his or her permission slip and one student's parents did not grant her permission to participate. No sampling occurred in the data collection process since data was collected from all students. The sample of students that was used represented a sample from all rural, public, Midwest junior high and high school LD/IEP students.

\section{Procedure}

Instruments. The instruments used for data collection involved student interviews. The interviews were conducted with a Dictaphone and were then later transcribed for use in this study. Interview questions were prepared beforehand to purposefully allow students to share their perspectives on the benefits and limitations that accompany a LD label. See Appendix A.

Data Collection Methods. One type of data collection occurred: in-depth interviews. These in-depth interviews were completed within a two-day period in which I took the day off of school and had a substitute teacher fill in while I interviewed during the school day. Each interview lasted approximately 10 to 15 minutes.

Relevant ethical considerations. This qualitative phenomenological research study did not cause any harm to the students involved. The interviews were solely based on opinions of how the students viewed his or her learning disabilities and how those learning disabilities affected them socially and academically. I was better able to 
understand the students' perceptions of the benefits and limitations to being labeled as LD and being on an IEP. Since the students I interviewed were minors, I sent home an informed consent form that had to be signed by the students' parents or legal guardian before participating. See Appendix B. The parents granted permission for their student to participate in the interview and have it dictated and later transcribed. Not only did I receive consent from the parents, but also the student as well. Parents and students alike were informed that the names of the students would remain confidential and would be changed in the write-up for their protection. Because these interviews were done in private, I would be the only one who would know his or her identity.

Treatment variable. The treatment variable was the Learning Disability labels and IEPs that the students have attached to their names at school. The assessed variables were the students' perceived benefits and limitations due to the LD labels and IEPs.

Methods of data analysis. Each of the interviews were transcribed and organized according to the question number and the individual being interviewed at that time.

In order to analyze the data, coding was completed to do so. Coding involved identifying specific mega-themes within the interviews. The first round of coding involved recognizing reoccurring themes and discarding the themes that did not occur as frequently. By the end of the coding process, a list of major codes emerged from the data.

Safeguards to internal and external validity. The students that were used in this study have a wide range of limitations and LD from low to high. This can most definitely affect their perceptions of being learning disabled and how greatly they allow that label to 
affect their lives. To maintain validity I interviewed as many of the students on IEPs at Franklin-Monroe High School that I possibly could.

In order to increase validity I also used words in my findings to closely mimic the word choices of the students. I also used several direct quotes from the students in order to make certain their own views were clearly established.

Unfortunately this study does face negative external validity issues. The findings of this study alone, is not enough to generalize to a larger population because there was no random sampling involved. The purpose of this study was not to generalize, but rather to inform those involved in education how exactly those who are labeled in school as having a learning disability are affected socially and academically. These results are able to somewhat generalize to schools with similar statures in size and location. 


\section{Chapter 4}

Qualitative Analysis

This study analyzed students’ perceptions of being labeled as Learning Disabled both socially and academically. In order to compare student reactions, in-depth interviews were conducted during a typical school day. The students included those who are on IEPs that attend one or more special education classes and those who are on IEPs that are fully included. Student participants included students ranging from the seventh grade to the twelfth grade in a small, rural, public school.

Analyzing the students' perceptions of being labeled as having a Learning Disability resulted in a variety of mixed responses. I found that the responses include both positive and negative benefits of being labeled with a Learning Disability. Students found much benefit by being labeled academically in some aspects. They felt it was beneficial by providing them with more opportunity for success in school. Some also felt that it had also hindered their learning because they felt behind regular education students. The majority of the students expressed how they would rather be in special education classes as opposed to regular education classes. An interesting response was noted when dealing with the social regards of being labeled. The majority of students agreed that they had a hard time making friends with the label, but mentioned how it also helped them in a way. 


\section{Description of Data}

In order to disclose the information I was seeking with each of the LD students, I conducted in-depth interviews. In order to gain a better understanding of each student's perspective, the interviews lasted 15-20 minutes and were tape recorded and transcribed for later analysis. Through comparison of the transcribed data, common themes quickly emerged. These common themes do not solve any of the continually problematic issues that lie within special education and students who have been labeled as LD, but they do give educators a better understanding of how students at a small, rural, public school view not only the benefits, but also the limitations of having a LD.

\section{Data Analysis}

The most common theme that emerged from well over one-half of the students interviewed was the main reason that they liked having a label and/or being in special education. Being equipped with the resources that each of these students have been given has allowed them to get the help that they need. These students like the fact that they get more help in special education and therefore have their school work explained more thoroughly. For example, Ashley stated: "In special education classes, the teacher explains it to you a lot more. You get more one-on-one time with your teacher.” This exact viewed was also shared by another student, James, who stated, "In special education, I like the fact that it actually helps you more with your homework and everything. When you are going over stuff, the teachers actually explain it better. This idea was confirmed by multiple students such as Brittany who stated that in special 
education, "the teachers usually explain things better to me." Micah stated the following: "I really don’t like the regular classes. They are kind of hard. I like special education, because I can actually do work in there and pass classes compared to the regular class. I think regular classes are much harder.” Chloe said, “I thought they (regular classes) were really hard...I dislike the difficulty of the regular classes.” The nature of special education is to allow students to find success. The majority of the students shared that grades in special education classes were better than regular education classes. The students attributed this to the extra one-on-one help that is received in the special education setting verses the inclusive setting. Clearly, the majority of these students find that success beneficial academically and like having a label or being in special education in order to meet that success.

The majority of the students interviewed shared that they would rather be in special education than in regular education. This was illustrated by Bo's comment. Bo said, "I would rather go to my special education classes, because I feel better about going and getting my work done.” The reasons given for this conclusion illustrated that being Labeled or being in special education allows the students to get their work done and actually meet success. One student named Bobby reinforced this by saying, "I can actually do work in there (special education) and pass classes compared to the regular education classes. (In regular education classes), I don't listen as well. I ignore what they (regular education teachers) are saying because sometimes I don't understand.” Another student commented on the fact that they are learning some life skills that other teachers do not teach. This student named Shanna stated, "You can learn things that other classes don't teach. Like right now in Carter's class, we were doing checks (writing them out, 
balancing the checkbook), and the other classes (regular education) you don't do that. Shanna liked this aspect because, "once you we get out there (real world) we will know how to do this.” Other students liked the aspect that having a LD or being in special education classes gives them more individual help. Susan stated that "regular education classes have a lot more people; there is not as much individual help.” Brandon reinforced this comment by stating, "The class is smaller so the teacher is talking more to you." Mary also commented that special education classes are more interesting to her than regular education classes because she, "has fun in it (special education)." Another student echoed by stating, "I like to be in there for the work and it’s pretty fun at times. And in Carter's class, we do some math games.”

Some of the students found that having a Learning Disability created a difficult time for them to make friends with regular education students. One student, Alexandra, expressed, "People think that you are stupid, so they don’t want to be your friend." Another student, Todd, responded in a similar manner stating, "Because we are not in the regular classes—in a way they look at me as stupid. Yet another student, Brianna, made the same comment saying, "Some people think we are stupid and just don't want to be our friends.” One individual sought to explain why some students make fun and tease them and "think that you are retarded.” She stated that "they teased me a lot, because they just don't understand, and they just think that I am different, so they just pick on the different kid.” She explained that many times teasing is a result of a misunderstanding between special education or learning disabled students and regular education students.

Many of the students found it difficult making friends with regular education students not only because those students (regular education) perceive special education 
and students with LD as "stupid" but also because many of them also get teased by the regular education students. One student, Mary, said that, “They (regular education students) used to tease me because I couldn't learn as fast as them and I had a speech impediment." Another student, Kim, said that "Sometimes, it (LD) can get you made fun of, because they say you don’t really know much, or call you an idiot.” Even though many of the students voiced that they found it difficult making regular education friends at times, the majority of the individuals expressed that they had "a lot" of friends. When I asked Samantha how many friends she had, she replied, “I can’t count—maybe over 200 (both online and at school).”

On the other hand, many of the students who expressed that having a LD or being in special education has limited them in his or her ability to make friends, also shared that it has also helped them in some aspects to make friends. Many students explained that sharing a LD with other students has brought them together and created friendships. More specifically Keira stated, "Other people that are LD know that I am LD and they can talk to me because they know that I am not that smart either.” Another young lady named Carrie said, "I’m friends with people I never thought I would be friends with.” For instance, Brent stated, "It makes you ask more smart people so you get to know them and you get to also know the people in your classes (special education). One student on an IEP, but not in special education, attends an intervention period each day in order to receive the extra help that is needed. Because this student (Mark) is in intervention with other students who are also on IEPs, he said that, "I've made some new friends in my study hall—-they are both on IEPs.” these students help one another with homework, reading tests aloud to one another and are simply there to aid the others with day-to-day 
school tasks. This allows for more peer-to-peer cooperative work in which peers tutor one another and in the process build friendships periodically.

Throughout the interviews students frequently made the point that they feel having a learning disability or being in special education has kept them from learning. One student, Bethany, said, “Sometimes they expect us to not move as fast. We're really not stupid, some people don't realize that." She expressed her frustration of the speed at which they move along in special education. The frustration felt by some of the students that they are viewed as "stupid," was common. Samantha echoed this view stating, "We are limited by what they think we can do and not by what we can do.” She went on to explain that, “sometimes we don't move on with the work because they think we need to repeat it, or they think we can't do it." Another student, Sierra said, "In these types of classes (special education), I just don’t think I’m learning enough.” Mark felt similarly saying, "I learn that my other class (regular education students) is ahead of where I am, so I'm trying to work up on my speed to get where they are at. I sometimes feel like I am behind where the regular classes are.” Lisa also felt the burden of being behind her fellow classmates by stating, “We don’t do stuff like other kids do—-the harder stuff. We do the easy stuff. I feel really behind the regular classes.”

The following chart displays the common themes that emerged from the data. Theme one represents that students would rather be in special education or be labeled as LD in order to receive better instruction and better grades (65.7\%). The second theme represents the number of students who feel that a learning disability label has kept him or her from learning (45.7\%). Theme three represents the number of special education students who would rather be in special education classes versus regular education 
classes (56.5\%). The fourth theme reveals the number of students who feel that his or her learning disability has hindered them from making friends by being teased (57.1\%). Lastly, theme five demonstrates the number of students who feel that having a learning disability label has enabled them to make friends (51.4\%).

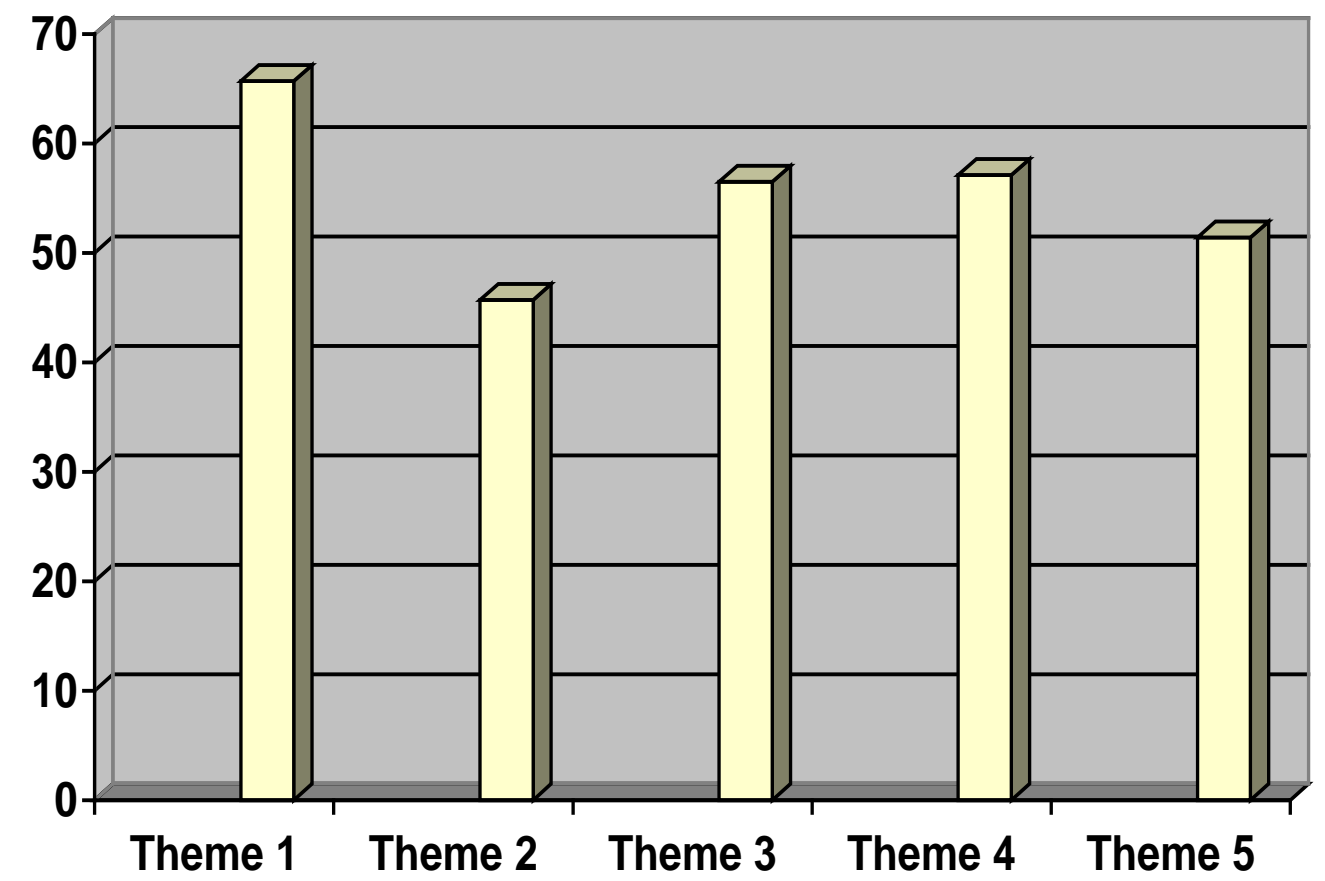

\section{Summary}

In conclusion, this study offered insight into the perceptions LD students' share both socially and academically. The benefits of being labeled as LD academically included extra help in special education classes and intervention periods and comprehending schoolwork. The social benefits of being labeled LD included helping the students make more friends. The academic limitations included being further behind the regular education students. The social limitations of being labeled LD being teased 
by regular education students, and sometimes have difficulty making friends with them.

Despite the fact that limitations were noted by the students, the vast majority still outweighed the benefits over the limitations and said that they would still rather be in special education in order to continue meet success in the classroom. 


\section{Chapter 5}

\section{Discussion and Limitations}

After analyzing the results of this phenomenological research, it is clear that the LD labels and special education can have adverse affects on students not only socially, but also academically. Although there are negative perceptions felt by the students interviewed, it is clear to see that the majority of them also enjoy the benefits of special education and/or having a LD, and would rather be in special education in order to meet success and get the much needed help. Overall, the limitations seemed minor compared to the success that they were able to achieve with the assistance of the special education department.

\section{Interpretation of the Results}

Meeting Success. Almost all of the students expressed that their grades were better in special education or have been brought up since the discovery of their LD. In order to do well in school, students have to understand what is happening in the classroom. Many of the students before arriving in special education or being labeled as LD basically tuned their teachers out in the regular education classroom. After discovering that they had academic difficulties, they were then able to receive the help that was much needed. The resources the special education department can offer outweighs all of the other negative perceptions associated with being labeled as LD. 
Almost all students mentioned the fact that they liked being labeled or being in special education for the mere fact that they were able to get things better explained, and they were now able to understand what was being taught and how to work with their disabilities.

Students prefer special education. Most of the students expressed that they would rather be in special education because they feel overwhelmed and/or have difficulty understanding in regular education classes. Because all of these students, whether in special education or not, are labeled as LD, they have some limitation that created a gap in their learning. After realizing their disability, the gap has been bridged by a label known as a LD and they have been placed on an IEP whether in the regular classroom setting, and/or in the special education classroom setting. The gap that once existed has been closed, allowing these students to better understand themselves and their own limitations. What was once impossible to these students has been made possible with the surrounding help of their regular education teachers, special education teachers, and peer tutors.

LDs hindered students from making friends. Because LD students have limitations that are sometimes magnified in the regular classroom, students have been known to be cruel and make fun of those who are "different.” Many LD students experience teasing from peers. Teasing is experienced by a vast array of students whether LD or not. The students that experienced torment from the other regular education students found it difficult to become friends with those individuals. It seems that this problem needs to be combated by educating students about LD. One student mentioned how she felt that regular education students didn’t “understand,” and how that 
lack of understanding of why LD students are "different” would many times lead to them being teased or made fun of. Teachers may need to spend some time with his or her students sharing about LD and special education, and why some students have to receive extra help. Having a LD, being on an IEP, or being in special education does not equate to stupidity, but rather another way of learning. With proper understanding of learning disabilities, teasing may be further limited.

LDs helped students make friends. While some LD students found it difficult to make friends with regular educations students, others found themselves creating more friendships due to his or her LD. Some students on IEPs receive peer to peer tutoring during homeroom time or during study halls. Through this peer tutoring, students found opportunities to create new friendships that once did not exist. Students also found opportunities to have close friends in special education along with regular education. The interviewed students were able to better understand other LD students and therefore form close friendships with those students along with the regular education students. Some students on IEPs found themselves friends with other students that they never imagined that they would be friends with. They never had the opportunity to become close with other LD students until they were in a special education class together or in an intervention period with them.

LDs limit student learning. Some students feel negatively impacted by their LD due to being limited to the amount of material that they can learn or have the opportunity to learn. When one student voiced her disappointment by being denied the opportunity to take a Spanish class due to her LD, she felt limited by her LD. Other students felt limited because they seemed behind the regular education students. This expressed 
disappointment could be minimized with further training for special education and regular education teachers in order to help students with LD meet the same standards other students do. One senior student commented how she did not like how the younger high school students held her back. She felt as though she was being limited by what she was learning because the younger students were holding her back. She and some of the others would be ready to move on to new concepts and lessons, while others lagged behind. In order for the special education teacher not to lose the younger students, the older ones expressed frustration by being limited in this aspect. Special education teachers and regular education teachers need further training in order to implement daily lesson plans that allow for differentiation. While this concept is still rather new in the world of education, differentiated lessons would definitely limit student frustration.

\section{Potential Applications of the Findings}

Teacher and student sensitivity. Teachers and regular education students alike need to consider the feelings of LD students and make certain efforts are made to make them feel included not only academically, but also socially. Many students expressed feeling behind the regular education students academically. Teachers and students need to make an effort in regular education to bring LD students up to speed. Ample time needs to be spent with them while in the regular education classroom with teacherstudent tutoring and student-student tutoring. They need to be included in class discussions and work just as regular education students are included. This may require more time and effort on the part of the educator, but it will help bring these students up to speed and make them feel like a part of the regular education class. 
Cooperative Learning. Cooperative Learning as in group work will provide opportunities for LD students to create positive relationships with regular education peers. Working together allows for students to get to know other individuals in class and learn how to work with each others' individual differences. Group work can be beneficial for all and allows students to learn how to work with individuals of different talents and needs. Students are not only responsible for why they learn, but they are also responsible for helping their teammates learn. Cooperative learning is encouraged not only in the work setting, but also in the educational setting to prepare individuals for realword situations.

Education on LDs. Teachers and regular education students also need to be educated on LDs. Regular education students and some LD students as well do not understand what it means to be labeled as LD or be on an IEP. By educating these students exactly what it means to have a LD, then some teasing may be eliminated. One of the students commented in her interview how some students pick on her and other students in special education because they lack understanding about the way LD students learn. Instead of shoving this concept under the rug, educators need to spend time at school talking about and sharing the different ways students learn. Not all students learn alike, therefore, it is necessary to bring those differences to the forefront and make sure everyone understands students with LD's are not stupid, they just learn differently.

This proper understanding is also necessary among regular education teachers. These teachers need to understand how to approach various LDs and how to teach to all students. Whether on and IEP or not, students learn differently and at different rates. Teachers need ample training in LDs in their college education programs. This will 
allow teachers to better understand students with LDs and teach based on individual needs.

Differentiated Lesson Plans. Teaching to meet student needs may be one of the most crucial aspects that may lead to positive student perspectives on his or her LD not only socially, but also academically. Teachers need to help students succeed not only in special education classroom settings, but also regular education settings. Teachers need to make a habit of creating lessons that give students opportunities to learn at his or her own rate. For example, to test, some students will do better demonstrating knowledge with projects, while others will do better taking tests. If teachers were given ample training on differentiation, they would be better equipped to teach to all abilities and talents. In this manner, students would find success and learn as much as their regular education peers by demonstrating knowledge in his or her best form or fashion. Teachers will also need to realize that this way of teaching will not be easy at first, but will take time to learn how to implement it into the classroom and also ample time to plan accordingly.

\section{Biblical Integration}

As a Christian educator in a public or private setting, it is imperative to remember that each and every one of our students are created in God's image. According to Genesis 1:27 God reveals that man is made in His image. That means we must take into account that each student we come into contact with are replicas of our Father in heaven. No matter what level of ability, talent, or intelligence, they are all made by God who has 
created them into His image alone. Genesis 1:27 states, "So God created man in his own image, in the image of God he created him; male and female he created them.”

Since all of mankind is made in God's image, I too must remember that I am an image bearer as well. As an educator I have a multitude of opportunities to mold the minds and lives of those I come into contact with. With this in mind it is my privilege as a believer to represent Christ as best as a fallen human being can. I must care for my students and portray their importance to each and every one of them, and celebrate their differences. God created them and it is not a misfortune that some have LDs and some do not. I need to instill the young minds that differences are not necessarily bad. Educators alike need to unite on this message whether in the public or private school, believer or not, and instill this common theme among regular education students and special education students.

\section{Relation of the Results to Literature}

Current literature findings showed mixed perceptions on the effectiveness of labels for students not only academically, but also socially. Some of the literature found that students often feel rejected by their peers when labeled with a LD (Zic \& Igric, 2001). In the current study many students found that having a LD created difficulty in making friends in the regular classroom. This difficulty in making friends was sometimes due to being teased by regular education students because of their LD.

Some studies concluded that individuals reported that students had fewer friends, and experienced social exclusion from their peers (Wainscot, Naylor, Sutcliffe, Tatam, \& Williams, 2008). Yet another article concluded that LD students are much more likely to 
experience loneliness than regular education students (Wiener, 2004). In the current study students expressed how having a LD actually aided in creating friendships. Instead of hindering them from friendships, it actually helped foster new ones. For example, some LD students expressed becoming friends with students who they received peer-topeer tutoring from. Others shared becoming friends with students they never imagined they would be friends with. For example, some LD students experienced relationships with students they shared intervention periods with and students in their small special education classes. Most of the students shared in their interviews that they had a multitude of friends ranging from special education students, to regular education students.

Another negative aspect that was brought to the forefront in the literature findings was that LD students felt behind academically compared to other students (Banks, \& Woolfson, 2008). Many of the students in this current research project supported this same idea. They felt academically they were behind regular education students. Another researcher voiced this same finding stating that students labeled as LD have problems with academic growth and achievement (Conley, 2007). Some of the interviewed students felt behind due to being labeled as LD. Some expressed frustration by sharing that they are limited by what others think they can learn, not by what they actually could learn. Some students simply felt they weren’t learning enough, therefore, felt academically behind the regular education students.

Being diagnosed with a LD in the current literature findings showed that some students do experience academic benefits from being labeled as LD. One girl expressed that when she was diagnosed with a LD, it was "like the sun coming out after a cold day 
of rain.” Another student within this same study found he no longer felt stupid (Lauchlan \& Boyle, 2008). The vast majority of students interviewed in this study also felt that being labeled with a LD or being in special education was beneficial. The majority of students actually preferred to remain in special education because of the imperative help that they receive in their education process. This desire by the students interviewed who preferred special education over regular education was not discussed in other studies.

While so much of the literature findings, painted an ugly picture of being labeled as $\mathrm{LD}$, it seems as though the students in the interviews found much more positives. Although students did bring up a couple common themes that were negative, the positives outweighed the negative for most who clearly stated they would rather be in special education than regular education. Academically, students expressed concerns of being behind the other students, but enjoyed the success that they experienced with the extra help in special education and by being labeled as LD. While some students expressed negative feelings of being teased by students and having a difficult time making friends with regular education students, the majority said that they did not have a difficult time making friends overall, and had vast array of friendships.

\section{Strengths of the Study}

This paper consisted of thirty-five in-depth junior high and high school interviews that allowed me to have a glimpse into the lives of those who are labeled as LD. Their thoughts and perceptions were best described by none other than themselves. Ample time was spent with each of the students which allowed for them to think through their answers and take their time. 
This research study focused on student perceptions in one small, rural school unlike previous studies. This study was even further limited to junior high and high school students. Students who were interviewed were all on IEPs, and therefore received some sort of special education services whether they were fully included in the regular education setting, or received classes in the special education classroom setting. By addressing secondary level students this allowed greater gain of insights for this particular age group in a small school setting. The results found in this study are therefore more applicable to junior high and high school LD and/or special education students at a small, rural school setting.

The methods of data collection involved saturation of data. Interviewing thirtyfive students allowed for extensive data to be used. The interviews were then transcribed word for word to ensure proper data accuracy. The transcribed data allowed for common themes to emerge that were used in this study. The number of interviews produced saturation because repeated results emerged from student. Additional interviews would not have likely produced any other novel findings.

\section{Limitations of the Study}

Remaining threats to internal validity. By using in-depth interviews, students were able to share valuable information that was detailed. Many of the students gave lengthy answers when asked the interview questions, while some of them gave very short and less detailed information. These students had to be prompted to expound on their answers and some were able to answer more thoroughly, and others were not. Although 
some students needed more prompting, enough data was collected to provide apt findings that represented the group’s consensus.

Since this study was conducted in a small, rural, public school setting, a relatively small data set was derived. I was able to interview only thirty-five students which included all but two students who either did not have permission to participate, or did not return the permission slip.

Remaining Threats to External Validity. As a result of the small number of students attending the school in which the interviews were conducted in, random selection could not be implemented into this study. All of the students involved consisted of all LD students in the school except for a couple who did not turn receive permission from a parent or guardian to participate in the interviews, or did not return his or her permission slip. As a result, all students were used within a very small setting, and therefore, it is difficult to generalize all students on IEPs in the United States. Therefore, others interested in this study cannot generalize this study for all high school populations. With this in mind, beneficial educational information can still be interpreted and used in classrooms across the states that are similar in size and location.

\section{Suggestions for Future Use}

For future research, this study should be expanded to include a greater number of schools with diverse groups of LD students. Also, how students perceive the special education resources as compared to other schools would be helpful in drawing comparisons among special education programs. 
Since this study focused on qualitative issues and found that overall, student perceptions of LD labels is fairly positive, it would be necessary to continue to analyze these effects in a quantitative manner. Students prefer special education, for example, over regular education mainly because of the extra help they receive. Now, actual academic effects that LD or special education has on learning should be assessed. This would encourage the qualitative findings reported in this present research.

Another area for future research would include analyzing special education and regular education teacher perspectives that regularly have LD students in the classroom. Their insights to what observations they note compared to the perceptive of the LD students' themselves would be interesting to compare. 


\section{APPENDIX A}

\section{INTERVIEW QUESTIONS}

1. Compare special education classes to regular education classes. What do you like about each and why?

2. What do you dislike about each (special education and regular education classes) and why?

3. Everyone learns differently. In what ways do you think that being labeled LD helps you learn? Give specific examples.

4. In what ways do you think that being labeled LD keeps you from learning? Give specific examples.

5. Compare your interest level in special education classes versus regular education classes. Does it change? If so, explain how?

6. Why do you think it changes in this manner (as mentioned above)?

7. Do you prefer special education classes over regular education classes? Explain

8. Do you prefer regular education classes over special education classes? Explain.

9. What grades do you earn in special education classes?

10. What grades do you earn in regular education classes?

11. In what ways do you think that being labeled LD helps you make friends?

12. In what ways do you think that being labeled LD keeps you from making friends?

13. How do you feel when you leave the room to take tests? 
14. How do other students (regular education) react when you leave the room to take tests?

15. Do students tease you and if so why? If so, give examples.

16. How many friends do you have? Are your friends LD as well or regular education students, or both? Explain.

17. How do you feel about yourself? What is your self-image? 


\section{APPENDIX B}

\section{PARENTAL CONSENT FORM}

October 23, 2008

Dear Parent/Guardian,

I hope that the beginning of the 2008-2009 school year has been enjoyable for you and your student. This summer I was working toward my Masters in Education at Cedarville University. This has been a beneficial experience, and I have been able to implement the various methods and ideas I have gained in my classes.

Now that I have completed all classes in the program, I am working on my thesis which is my final project. To better serve students in the special education program, I will be interviewing student perceptions of being labeled as learning disabled (LD). Special education services have been in existence for a number of years, but the research on the effects of being labeled as LD is limited and many times inconclusive.

In order to better serve your student as an educator, I will conduct a 20 minute interview with each student in the special education department. Most of these will be conducted before school or after school. Some interviews will be conducted during homeroom or their study hall if it coincides with my prep period.

At this time I am requesting your permission for your student to have his/her interview taped and transcribed. All information from the interview will be kept confidential and names will be changed in any reports. Please sign and return the permission slip below by Wednesday November 12. I appreciate your cooperation. Please feel free to contact me by e-mail or phone. My e-mail is Ashley_matheson@darke.12.oh.us, and the phone number at school is 692-8761.

Sincerely,

Mrs. Matheson

I give permission for my student to participate in an interview regarding his/her perceptions of LD labels and special education. I also grant permission for the interviews to be taped and transcribed. I understand that confidentiality will be maintained.

Student's name:

Date:

Parent's signature: 


\section{REFERENCES}

Bakker, J.T., Denessen, E., Bosman, A.M., Krijger, E.M., \& Bouts, L. (2007).

Sociometric status and self-image of children with specific and general learning disabilities in Dutch general and special education classes. Learning Disability Quarterly, 30(1), 47-62.

Banks. (2008). Why do students think they fail? The relationship between attributions and academic self-perceptions. British Journal of Special Education, 35(1), 49-56.

Bear, G. G., Minke, K.M., \& Manning, M.A. (2002). Self-concept of students with learning disabilities: A meta-analysis. School Psychology Review, 31(3), 405.

Bryan, T., Burstein, K., \& Eurgul, C. (2004). The social-emotional side of learning disabilities: A science-based presentation of the state of the art. Learning Disability Quarterly, 27(1), 45-51.

Conley, T. D., Ghavami, N., VonOhlen, J., \& Foulkes, P. (2007). General and domain-specific self-esteem among regular education and special education students. Journal of Applied Social Psychology, 37(4), 775-789.

Elbaum, B. (2002). The self-concept of students with learning disabilities: A metaanalysis of comparisons across different placements. Learning Disabilities Research and Practice, 17(4), 216-226.

Fore, C., Hagan-Burke, S., Burke, M.D., Boon, R.T., \& Smith, S. (2008). Academic 
achievement and class placement in high school: Do students with learning disabilities achieve more in one class placement than another? Education and Treatment of Children, 31(1), 55-72.

French, S. (2008). Visually impaired people with learning difficulties: Their education from 1900 to 1970--Policy, practice and experience. British Journal of Learning Disabilities, 36(1), 48-53.

Ho. (2004). To be labeled, or not to be labeled: that is the question. British Journal of Learning Disabilities, 32(2), 86-92.

Holloway, J.H. (2001). Inclusion and students with learning disabilities. Educational Leadership, 58(6), 86-88.

Irvine, P., Wright, E. B., \& Applequist, K. (2007). History of special education. In C.R. Reynolds \& E. Fletcher-Janzen (Eds.), Encyclopedia of special education (pp. 1042-1049). Hoboken, NJ: John Wiley \& Sons.

Lauchlan, F., \& Boyle, C. (2007). Is the use of labels in special education helpful? Support for Learning, 22(1), 36-42.

Linn, R. L. (2002). Accountability systems: Implications of requirements of the No Child Left Behind Act of 2001. Educational Researcher, 31(6), 3-16.

Mayton, M. R. (2005). The quality of life of a child with asperger's disorder in a general education setting: A pilot case study. The International Journal of Special Education, 20(2), 85-101. 
Meltzer, L., Reddy, R., Pollica, L.S., Roditi, B., Sayer, J., \& Theocas, C. (2004).

Positive and negative self-perceptions: Is there a cyclical relationship between teachers' and students' perceptions of effort, strategy use, and academic performance? Learning Disabilities Research and Practice, 19(1), 33-44.

Mrug. (2002). Self-Concept of young people with physical disabilities: does integration play a role? International Journal of Disability Development and Education, 49(3), 267-280.

Raskind, M.H., Margalit, M., \& Higgins, E.L. (2006). My LD: Children’s voices on the internet. Learning Disability Quarterly, 29(4), 253-268.

Rea, P.J., McLaughlin, V.L., \& Walther-Thomas, C. (2002). Outcomes for students with learning disabilities in inclusive and pullout programs. Exceptional Children, 68(2), 203-223.

Reid, D.K., \& Button, L.J. (1995). Anna’s story: Narratives of personal experience about being labeled learning disabled. Journal of Learning Disabilities, 28(10), 602-615.

Schmidt, M., \& Čagran, B. (2008). Self-concepts of students in inclusive settings. International Journal of Special Education, 23(1), 8-17.

Swanson, H.L., \& Edelston, D. (2007). Learning disabilities. In C.R. Reynolds \& E. Fletcher-Janzen (Eds.), Encyclopedia of special education (pp. 1231-1234). Hoboken, NJ: John Wiley \& Sons. 
Trainor, A.A. (2007). Perceptions of adolescent girls with LD regarding selfdetermination and post-secondary transition planning. Learning Disability Quarterly, 30(1), 31-45.

Vergason, G.A., \& Anderegg, M.L. (1997). Dictionary of special education and rehabilitation (fourth edition). Denver: Love Publishing Company.

Wainscot, J. J., Naylor, P., Sutcliffe, P., Tantam, D., \& Williams, J. V. (2008). Relationships with peers and use of the school environment of mainstream secondary school pupils with asperger syndrome (high-functioning autism): A case-control study. International Journal of Psychology \& Psychological Therapy, 8(1), 25-38.

Westby, C. \& Blalock, E. (2005). Assessment of social-emotional status in children with language impairments. Seminars in Speech and Language, 26(3), 160-169. Wiener, J. (2004). Do peer relationships foster behavioral adjustment in children with learning disabilities? Learning Disability Quarterly, 27(1), 21-30.

Winterman, K.G., \& Sapona, R.H. (2002). Everyone’s included. Teaching Exceptional Children, 35(1), 30-36.

Zic, A., \& Igric, L. (2001). Self-assessment of relationships with peers in children with intellectual disability. Journal of Intellectual Disability Research, 45(3), 202211. 